\title{
Molecular cloning and identification of the hatching enzyme gene in Rondotia menciana
}

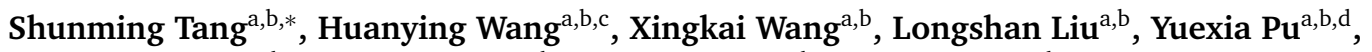 \\ Xuezheng Wang ${ }^{\mathrm{a}, \mathrm{b}}$, Qiaoling Zhao ${ }^{\mathrm{a}, \mathrm{b}}$, Jialing Cheng, ${ }^{\mathrm{a}, \mathrm{b}}$, Xingjia Shen ${ }^{\mathrm{a}, \mathrm{b}}$ \\ a Jiangsu Key Laboratory of Sericultural Biology and Biotechnology, School of Biotechnology, \\ Jiangsu University of Science and Technology, Zhenjiang 212003 China \\ b Key Laboratory of Silkworm and Mulberry Genetic Improvement, Ministry of Agriculture, \\ Sericultural Research Institute, Chinese Academy of Agricultural Sciences, Zhenjiang 212018 China \\ c Zhejiang Tianke Technology Development CO., LTD, Hangzhou 310012 China \\ d Guangxi General Station for Sericulture Technology Popularization, Nanning Guangxi 530007 China
}

*Corresponding author, e-mail: tangshunming2002@163.com

Received 1 Feb 2018

Accepted 15 Aug 2018

\begin{abstract}
Rondotia menciana Moore (Lepidoptera: Bombycidae) is a major pest of mulberry. We cloned the fulllength cDNA of the hatching enzyme from $R$. menciana eggs (RmHE) using the RACE-PCR and SMART cDNA synthesis technique. The cDNA is 1325 bp long and contains an ORF of 885 bp. It encodes 294 amino acid residues, including a putative signal peptide of 16 amino acid residues. Two conserved signature sequences of insect hatching enzyme (HE) harbour in the RmHE. The deduced amino acid sequence of RmHE has 30-84\% identity to HE sequences in other insect species, and RmHE is most similar to that of wild silkworm HE. RmHE transcripts could be detected in R. menciana eggs at different developmental stages. Levels remained low during the early stages, increased greatly in 7-d eggs, and reached a maximum in 9-d eggs. Changes in the levels of RmHE transcripts occurred in accordance with the process of embryo development and eclosion. This indicated that RmHE plays an important role in these processes. RmHE transcripts were also detected in larval midguts, suggesting that RmHE is involved in food digestion. As far as we know, this is the first report on an $H E$ gene in Lepidopteran pests and will offer some basic information for developing an efficient control method during the hatching process for agricultural Lepidopteran pests.
\end{abstract}

KEYWORDS: expression pattern, Lepidopteran pests

\section{INTRODUCTION}

The hatching phenomenon exists in almost all animals during the late development stage of the embryo. Hatching occurs when individuals transform from capsules to a free-living state, and it is significant for postembryonic development. During eclosion, a hatching enzyme (HE) proteinase is secreted by the embryo. The HE digests or softens the eggshell, which facilitates successful eclosion ${ }^{1,2}$. Most HEs belong to the astacin family and are Zn-metalloproteinases characterized by the consensus sequences HExxHxxGFxHExxRxDR (the zinc-binding motif) and SxMHY (the methionine turn $)^{3,4}$.

The hatching mechanism has been studied in fish $^{5-8}$, crustaceans $^{9,10}$, birds ${ }^{11}$, amphibians ${ }^{12-14}$, echinoderms $^{15}$, insects ${ }^{16-18}$, and mammals ${ }^{19,20}$. Rondotia menciana Moore (Lepidoptera: Bombycidae) is a major pest of mulberry ${ }^{21}$. Control of
$R$. menciana is mainly achieved by trapping and insecticide applications ${ }^{22,23}$. However, insecticide use can cause environmental pollution and eventually leads to pesticide resistance. Biotechnologybased pest management could be a better choice ${ }^{24}$. The hatching enzyme gene might provide a target for molecular manipulation and pest control at the embryo stage.

We have characterized HE in several Lepidopterans, including the silkworm, Bombyx mori ${ }^{25,26}$, Chinese Oak silkworm, Antheraea pernyi ${ }^{27}$, and Chinese wild silkworm, B. mandarina ${ }^{28}$. In the present study, we cloned the full-length cDNA of the $H E$ gene from bluish-eggs of $R$. menciana. We characterized the gene using bioinformatics and identified its possible biological function at the mRNA level. To the best of our knowledge, this is the first report of the $H E$ gene in Lepidopteran pests and will be useful for providing a molecular basis for understanding 
Table 1 Oligonucleotide primers used in the experiments.

\begin{tabular}{ll}
\hline Primer name & $5^{\prime}-3^{\prime}$ nucleotide sequence \\
\hline InsectHE F1 & gccsaacracaccgtygtytggga \\
InsectHE R1 & acwcytcgtgytccykcagagc \\
RmHE3'SP1 & catcgaaaggcacacatgtgtca \\
RmHE3'SP2 & ggatgctatgcccacgtcggcta \\
3'RACE Outer $^{\prime}$ Primer taccgtcgttccactagtgattt \\
3'RACE Inner $^{\prime}$ Primer cgcggatcctccactagtgatttcactatagg \\
RmHE5'SP1 & gtccgttctgtgagaatgcgtga \\
UPAM'Long & ctaatacgactcactatagggcaagcagtggtatcaacgcagagt \\
UPAM Short & ctaatacgactcactatagggc \\
Rmactin3-F & ggatgtccacgtcgcactt \\
Rmactin3-R & gcgcggctactcgttcact \\
\hline
\end{tabular}

${ }^{\dagger} \mathrm{UPAM}=$ Universal Primer A Mix.

the complicated mechanism underlying $R$. menciana hatching and for controlling $R$. menciana damage to mulberry. It also brings some clues for developing an efficient control method at hatching for the other agricultural Lepidopteran pests on main crops.

\section{MATERIALS AND METHODS}

\section{Materials and reagents}

R. menciana were collected from mulberry fields of the Sericultural Research Institute, Chinese Academy of Agricultural Sciences (SRI-CAAS). Escherichia coli (Top10) was maintained in our laboratory. RNAiso Plus, restriction enzymes, pMD18-T vectors, T4 DNA ligase, PrimerScript reverse transcriptase, and a ${ }^{\prime}$ RACE Kit were obtained from the Takara Company. An SMARTer 5'RACE Kit was purchased from Clontech. DEPC was purchased from Invitrogen. All PCR primers and DNA sequencing were accomplished by Shanghai Sangon Biological Engineering Technology \& Services Co., Ltd. All chemicals used were of analytical grade.

\section{Total RNA isolation and synthesis of the first-strand cDNA}

Total RNA was isolated from bluish-eggs of $R$. menciana using the RNAiso Plus reagent following manufacturer instructions. The quality of the total RNA was determined by the $260 / 280$ absorbance ratio as well as by electrophoresis ${ }^{29}$. Extracted RNA was stored at $-80^{\circ} \mathrm{C}$ until subsequent experiments.

The cDNA was synthesized from $1 \mu \mathrm{g}$ of total RNA by PrimerScript reverse transcriptase with an oligo-dT-adapter primer following the manufacturer's protocol. The cDNA was used as the template for PCR in gene cloning.

\section{Molecular cloning of RmHE cDNA}

Based on the conserved sequences of $H E$ identified in Lepidoptera, the degenerate primers of InsectHE
F1, InsectHE R1 (Table 1) were synthesized. Using the first-strand cDNA as the template, PCR was conducted. The cycling protocol for PCR was the following: 1 cycle at $94^{\circ} \mathrm{C}$ for $3 \mathrm{~min} ; 5$ cycles at $94^{\circ} \mathrm{C}$ for $30 \mathrm{~s}, 50^{\circ} \mathrm{C}$ for $30 \mathrm{~s}$ and $72^{\circ} \mathrm{C}$ for $30 \mathrm{~s}$; then 30 cycles at $94^{\circ} \mathrm{C}$ for $30 \mathrm{~s}, 55^{\circ} \mathrm{C}$ for $30 \mathrm{~s}$ and $72^{\circ} \mathrm{C}$ for $30 \mathrm{~s}$; and a final extension step of $10 \mathrm{~min}$ at $72^{\circ} \mathrm{C}$. The PCR products were analysed on $1 \%$ agarose gels and purified using the glass-milk method ${ }^{30}$. The purified fragment was then cloned into the pMD18$T$ vector and sequenced.

To obtain the 3 -end sequence of RmHE cDNA, a $3^{\prime} \mathrm{RACE}$ experiment was carried out according to the Takara $3^{\prime}$ RACE Kit User Manual. Outer PCR was performed with the $3^{\prime}$ RACE outer primer and the specific primer RmHE3'SP1 (Table 1). Inner PCR was performed with a $3^{\prime}$ RACE inner primer and the specific primer RmHE3'SP2 (Table 1). The PCR products were purified, cloned, and sequenced as described above.

The Clontech SMARTer 5'RACE Kit protocol was used for cloning the $5^{\prime}$-end sequence of $R m H E$ cDNA. Using the $5^{\prime}$ RACE cDNA as a template, PCR reactions were performed with Universal Primer A mix and specific primer RmHE5'SP1. PCR products were purified, cloned, and sequenced as described above.

\section{Bioinformatics analysis}

Basic properties, such as the splicing of sequence, searching of the ORF and translation of the nucleotide sequence, as well as isoelectric point prediction and the molecular weight of RmHE were determined using DNAStar software. Signal peptide was identified by the SignalP 4.1 Server (www.cbs. dtu.dk/services/SignalP/). Prediction of the threedimensional structure of the RmHE protein was accomplished by SWISS-MODEL ${ }^{31}$ (swissmodel. expasy.org/), and the Ramachandran plot was analysed by PROCHECK (nihserver.mbi.ucla.edu/ SAVS/).

$H E$ cDNA sequences of other species were retrieved from the NCBI database. Multiple sequence alignments were carried out using ClustALX. A phylogenetic tree was constructed based on the amino acid sequences by MEGA 4 using the neighbourjoining method with a bootstrap test of 1000 replications.

\section{Semi-quantitative RT-PCR analysis}

To study the transcript levels at different embryo development stages of RmHE, semi-quantitative RTPCR was carried out. One microgram of total RNA, 
separated from embryos at different development stages, was converted into cDNAs according to manufacturer instructions. The house-keeping Rmactin 3 gene was used as a reference to minimize differences among samples. PCR reactions were carried out under the following conditions: 1 cycle at $94^{\circ} \mathrm{C}$ for $3 \mathrm{~min}, 25$ cycles at $94^{\circ} \mathrm{C}$ for $30 \mathrm{~s}, 58^{\circ} \mathrm{C}$ for $30 \mathrm{~s}$ and $72^{\circ} \mathrm{C}$ for $1 \mathrm{~min}$, with a final extension step of $10 \mathrm{~min}$ at $72^{\circ} \mathrm{C}$. The primers for $R m H E$ and Rmactin 3 were RmHE5'SP1 and RmHE3'SP1, Rmactin3-F and Rmactin3-R (Table 1), respectively. The electrophoresis bands of PCR products were analysed by gel-Pro analyser software.

\section{Expression profile of $\mathrm{RmHE}$}

We investigated the expression profile of RmHE in different tissues of $R$. menciana, using RT-PCR. Total RNA was isolated from the cuticle, posterior silk gland, fat body, midgut, and haemolymph. The PCR conditions were as described above.

\section{RESULTS}

\section{Molecular cloning of RmHE cDNA sequence}

Using the degenerate primers of InsectHE F1, InsectHE R1 (Table 1), a single band of 518 bp was amplified by PCR with first-strand cDNA from $R$. menciana. The deduced amino sequence of the cloned fragment included 2 similar signature sequences of the hatching enzyme, which indicated that $R m H E$ mRNA exists in $R$. menciana.

Through the 3'RACE and 5'RACE methods, a full-length RmHE cDNA sequence of $1325 \mathrm{bp}$ was obtained (Fig. 1) (GenBank Accession No. KJ642218). This contained a $5^{\prime} \mathrm{UTR}, 3^{\prime} \mathrm{UTR}$ and an intact ORF of 885 bp. The starting base of the $5^{\prime}$ UTR was A, which is consistent with previous results showing that the transcription start site is typically a purine (A or G). In the $3^{\prime} \mathrm{UTR}$, there was the polyadenylation signal, AATAAA. The ORF encodes 294 amino acids residues with a molecular weight of $33.41 \mathrm{kDa}$ and an isoelectric point of 5.80 . At the N-terminus of RmHE, there is a predicted signal peptide of 16 amino acids. The cleavage site is located between Gly16 and Thr17.

\section{Homologous alignment and phylogenetic analysis}

Homologous analysis results of the deduced protease domain showed that RmHE has identity of $84 \%, 82 \%, 80 \%, 74 \%, 45 \%, 42 \%, 34 \%, 33 \%$, $33 \%, 32 \%, 32 \%, 32 \%, 32 \%$ and $30 \%$ to BmandHE, BmHEL, ApHEL, BmHELII, CuefHCE, DmHEHS,

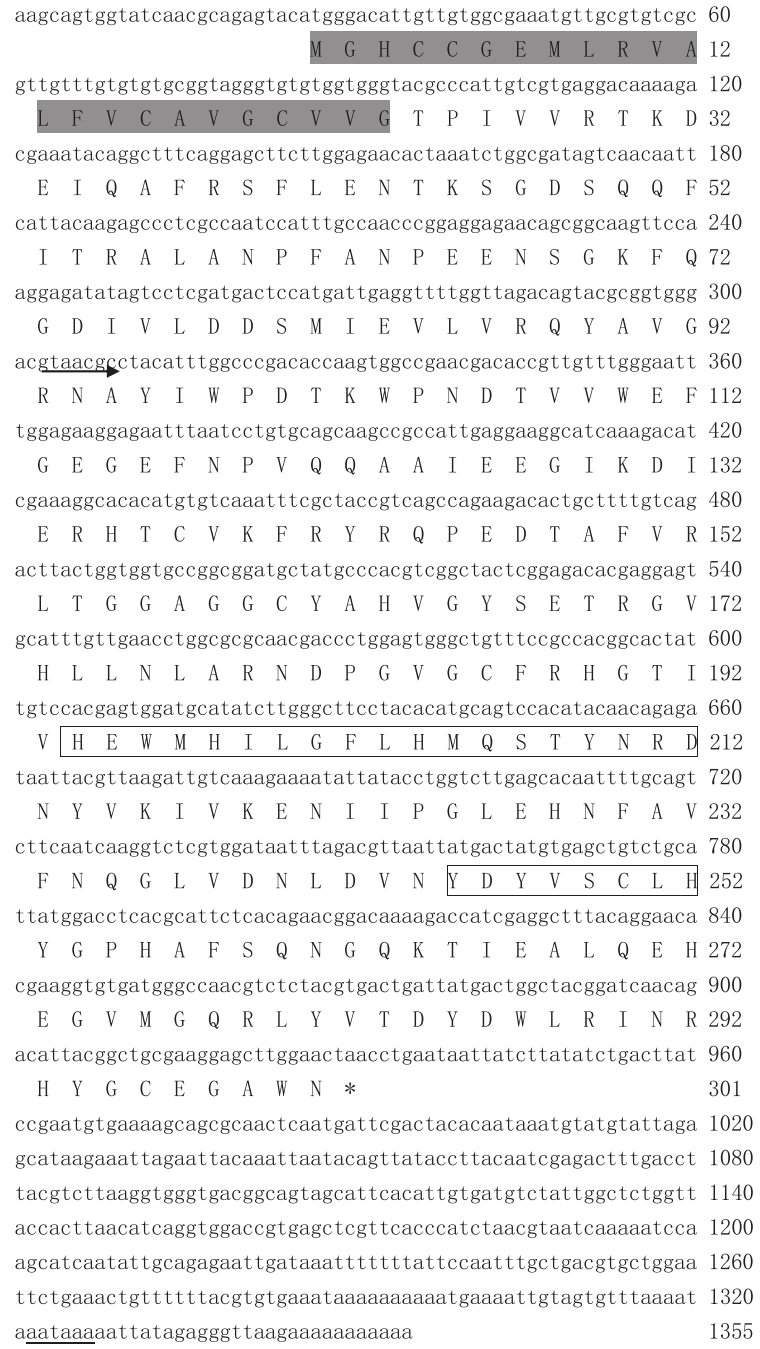

Fig. 1 RmHE cDNA sequence and its deduced amino acid residues. Astacin family signature motif sequence was boxed; the spark showed the stop code. The polyadenylation signal sequence (AATAAA) is underlined and highlighted, the signal peptide is shadowed, and the mature enzyme fragment starts from the arrow region.

XHE, MLCE, MHCE23, EHE12, ZHCE1, TuHE, QHE and astacin, respectively. Fig. 2a compares the amino acid sequence of RmHE with the sequences of HE of silkworm, wild silkworm, Chinese oak silkworm, fruit flies, mosquito, turtle, quail, fish, Xenopus, and astacin, respectively. Two similar signature sequences of HE, HEWMHILGFLHMQSTYNR and YDYVSCLHY, were found in the RmHE. Four cysteine residues were also found which are conserved in all astacin family proteases.

Fig. 2b shows the phylogenetic tree constructed using the neighbour-joining method. HEs were 


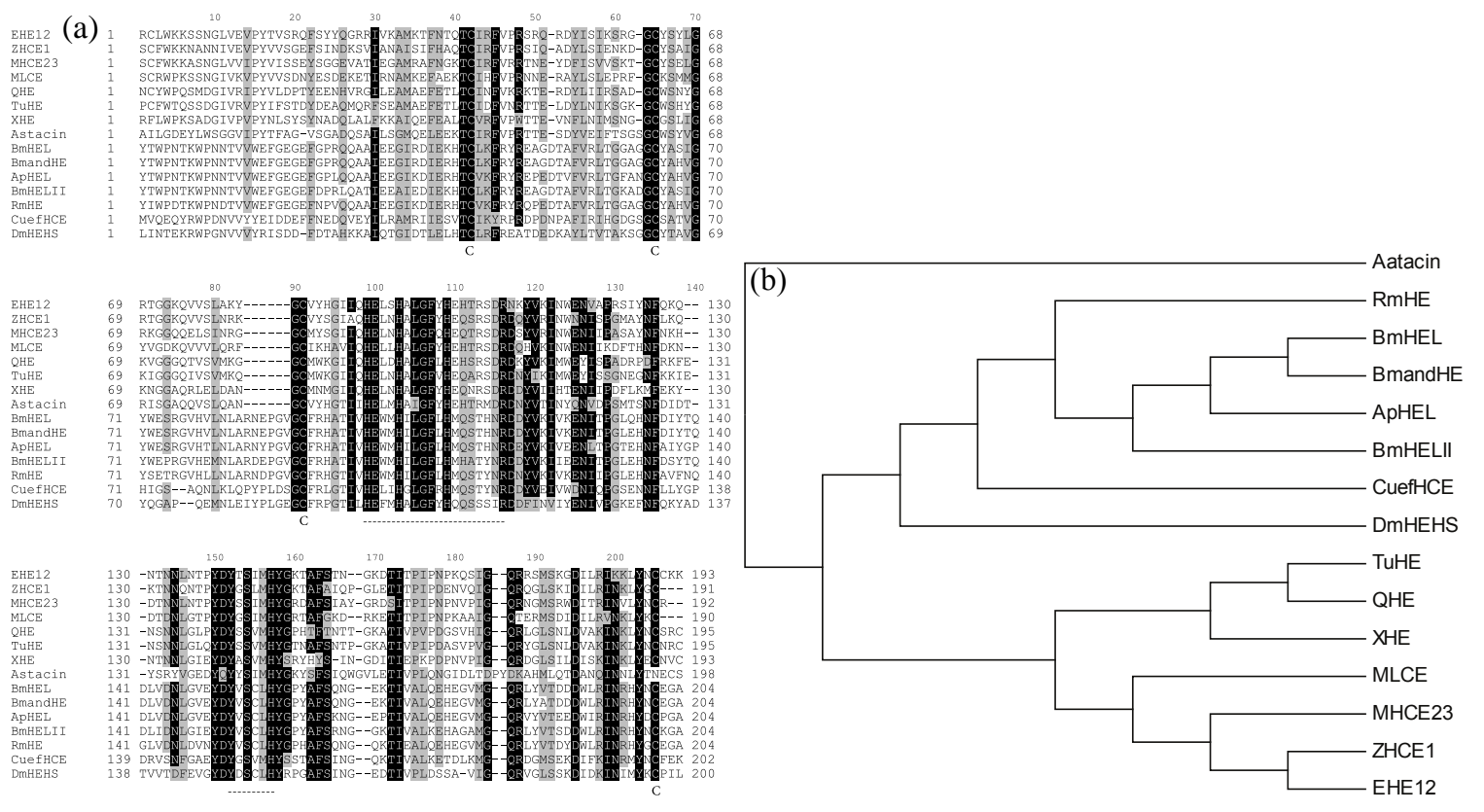

Fig. 2 Comparison of RmHE with other hatching enzymes. (a) Alignment of the amino acid sequences of mature protease domains. (b) A phylogenetic tree based on the protease domains of hatching enzymes. BmHELII Bombyx mori hatching enzyme-like II(GenBank accession No. JN627443), BmHEL B. mori hatching enzyme-like (FJ147197), BmandHE B. mandarina hatching enzyme (JN620366), ApHEL Antheraea pernyi hatching enzyme-like (JN205047), CuefHCE house mosquito high choriolytic enzyme 1 (XP_001844559), DmHEHS Drosophila melanogaster hatching enzyme homology sequence (NM135911), QHE quail hatching enzyme (BAD95472), TuHE turtle hatching enzyme(BAD95471), XHE Xenopus hatching enzyme (BAA14003), EHE12 eel hatching enzyme (BAB68517), ZHCE1 zebrafish hatching enzyme (NP_998800), MHCE23 medaka high choriolytic enzyme(P31580), MLCE madaka low choriolytic enzyme (NP_001098292), astacin (CAB43519).

clearly classified into two groups. $R$. menciana, silkworm, wild silkworm, Chinese oak silkworm, fruit flies and mosquito were clustered together into the invertebrate group. The vertebrate HEs clustered into a second group. R. menciana is most closely related to the wild silkworm and this was consistent with analysis of other genetic markers. HE is an appropriate candidate gene for phylogenetic analysis of fish $^{32}$ and may also be useful for phylogenetic analysis of insect groups.

\section{The three-dimensional structure of $R m H E$}

The amino acid sequence of RmHE was submitted to SWISS-MODEL (swissmodel.expasy.org/), and the three-dimensional structure of the RmHE protein (Fig. 3b) was constructed based on the crystal structure of the zebrafish hatching enzyme 3lqbA ${ }^{33}$ (Fig. 3a), which has an identity of $31 \%$ to that of RmHE. The protein model was evaluated by PROCHECK (nihserver.mbi.ucla.edu/SAVS/), and the Ramachandran plot provided a visual representation of conformation of amino acid residues, which evaluate the quality of the simulation model. Good quality models typically have over $90 \%$ of residues in the allowed regions. The simulated three-dimensional structure of RmHE has $98 \%$ in the reasonable area of the Ramachandran, which suggests that the simulated RmHE protein is theoretically reliable (Fig. 3c).

\section{Change of $R m H E$ transcript level in embryos}

To investigate the relative of $R m H E$ transcript in embryos at different development stages, a semiquantitative PCR technique was employed. The transcript of RmHE was maintained at a low level in the early embryo and then dramatically increased to a maximum just prior to eclosion (Fig. 4). The strict temporal pattern of RmHE expression was consistent with the possible role of the $H E$ gene.

\section{Expression profile of RmHE in different tissues}

Fig. 5 shows the expression profile of RmHE in different tissues of 5 th instar $R$. menciana larvae. The expected 394 bp DNA fragment was detected in the 

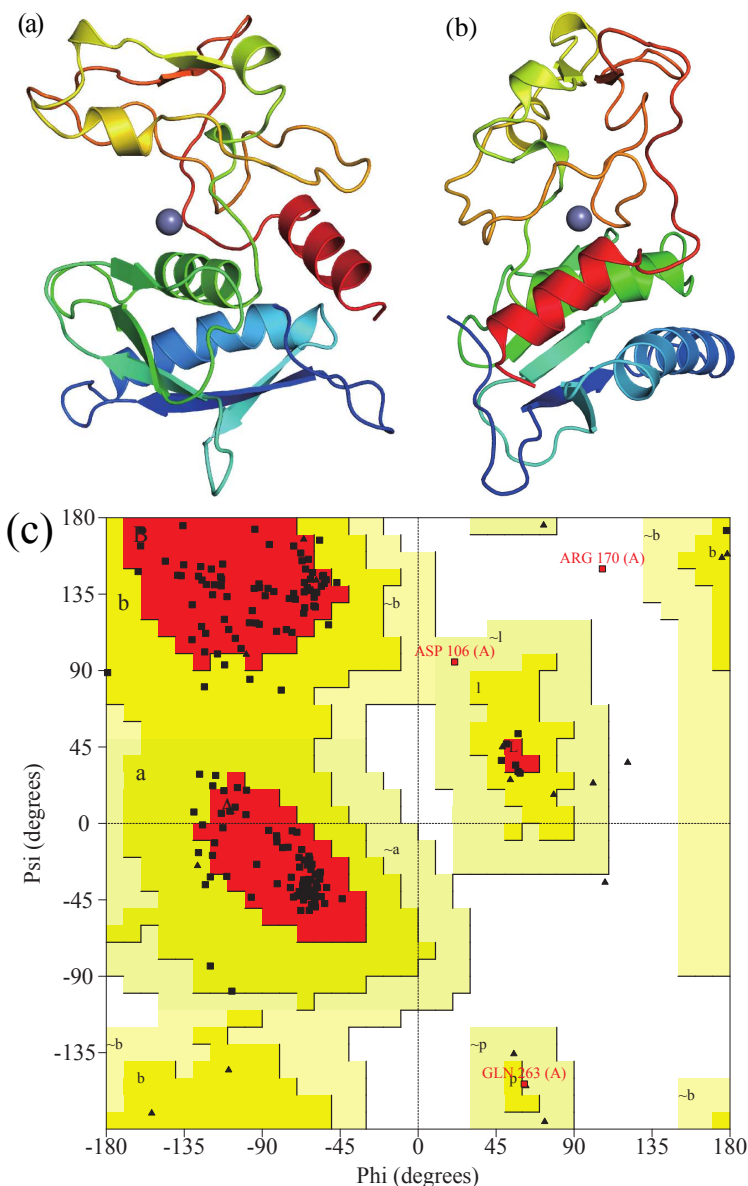

Fig. 3 The prediction of three-dimensional structure of RmHE protein. (a) The three-dimensional structure of 3lqbA protein (template); (b) The three-dimensional structure of RmHE protein; (c) Ramachandran plot, residues in most favoured regions[A,B,L](84\%); residues in additional allowed regions[a,b,l,p](14\%); residues in generously allowed regions $[\sim a, \sim b, \sim 1, \sim p](1 \%)$; residues in disallowed regions(0.6\%).

midgut, but could not be amplified from the cuticle, posterior silk gland, fat body or haemolymph. These results suggested that RmHE might be involved in food digestion.

\section{DISCUSSION}

The full-length cDNA of $H E$ was cloned successfully from $R$. menciana. Comparison of RmHE to HEs from other insects showed that these proteins share two signature sequences: a zinc-binding motif HExxHxxGFxHxxxxxxR and a methionine turn SxxHY. In the astacin family, these were HExxHxxGFxHExxRxDR and SxMHY. The subtle
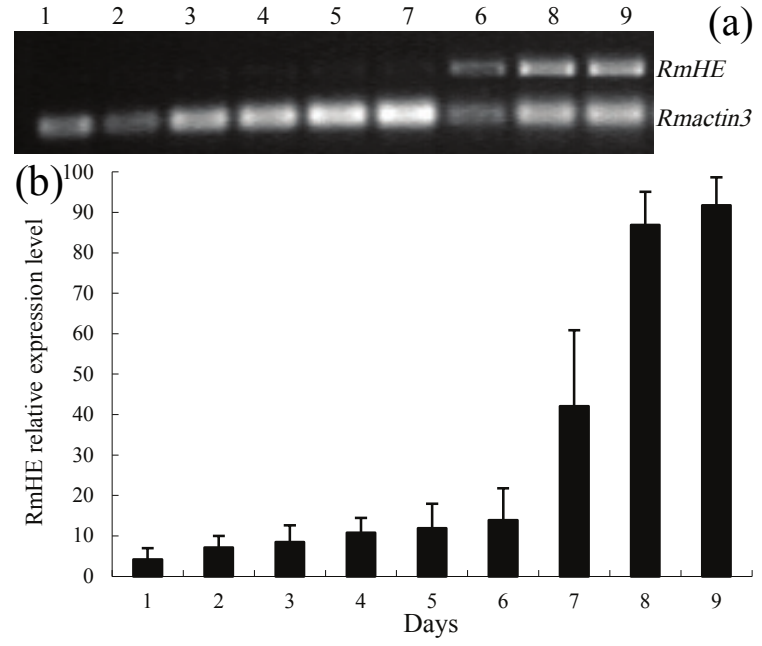

Fig. 4 Change of RmHE transcript level in embryo at different development stages. (a) Semi-quantitative RTPCR products of RmHE; (b) RmHE relative expression level. (1-9) the days prior to hatching, at 9th day, hatching occurred.

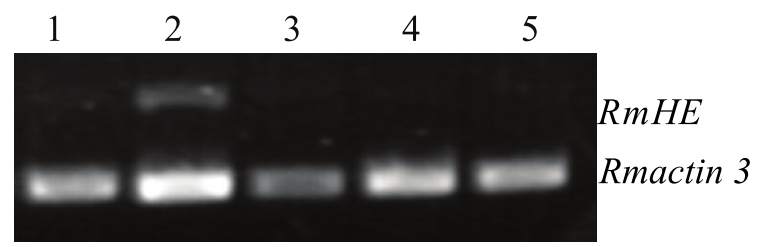

Fig. 5 Expression profile of RmHE in different tissues at 5 th instar of larval stage. 1\% agarose gel analyses of RmHE amplifications in comparison with those of controls (Rmactin 3), (1) cuticle; (2) midgut; (3) posterior silk gland; (4) fatbody; (5) haemolymph.

differences may have resulted from gene mutation, selection and species adaptation to unique environments over evolutionary time ${ }^{32}$.

Expression of RmHE was low in early embryos and then increased and reached a maximum just prior to eclosion. The spatiotemporal expression pattern of the RmHE gene resembles that of the hatching enzyme gene found in other species ${ }^{6}$. Expression of RmHE was observed in the midgut of 5th instar larvae but was not detected in other tissues. Two kinds of protein, embryonic astacin ${ }^{34}$ and digestive enzyme astacin ${ }^{35}$, were found in embryos and adults of the crayfish Astacus astacus. We found that the RmHE cDNA in the midgut was the same as that in the embryo, which implied that RmHE might have a digestive function. Similar results were found in the silkworm and Chinese oak 
silkworm $^{25,27}$. The small amounts of testis tissue in $R$. menciana larvae makes it difficult to c ollect. It therefore remains unclear if the second type of $\mathrm{HE}$ exists in the testis of $R$. menciana as it does in the silkworm $^{26}$.

Based on the presence of metalloproteases at the time of egg eclosion and the inhibition of egg eclosion in Pediculus humanus by metalloprotease inhibitors, therapeutic agents against some parasites could be developed from metalloprotease inhibitors ${ }^{16}$. For Lucilia cuprina, the use of rational drug design may lead to a shift away from the use of toxic chemicals towards the use of highly specific i nhibitors ${ }^{36}$. This study is the first report on the $H E$ gene in a Lepidopteran pest and provides basic information that may aid in the discovery and development of a method to disrupt the egg eclosion of $R$. menciana and other pest Lepidopterans.

Acknowledgements: This work was supported by the National Natural Science Foundation of China (Grant No. 31372376), the Natural Science Foundation of Jiangsu Province (Grant No. BK20141285), and the Graduate Research and Innovation Projects Foundation of Jiangsu Province (Grant No. CXLX13_701).

\section{REFERENCES}

1. Yasumasu S, Iuchi I, Yamagami K (1989) Purification and partial characterization of high choriolytic enzyme (HCE), a component of the hatching enzyme of the teleost, Oryzias latipes. J Biochem 105, 204-11.

2. Yasumasu S, Iuchi I, Yamagami K (1989) Isolation and some properties of low choriolytic enzyme (LCE), a component of the hatching enzyme of the teleost, Oryzias latipes. J Biochem 105, 212-8.

3. Inohaya K, Yasumasu S, Araki K, Naruse K, Yamazaki K, Yasumasu I, Iuchi I, Yamagami K (1997) Speciesdependent migration of fish hatching gland cells that express astacin-like proteases in common. Dev Growth Differ 39, 191-7.

4. Semenova SA, Rudenskaia GN (2009) The astacin family of metalloproteinases. Biochem Moscow Suppl Ser B 3, 17-32.

5. Kawaguchi M, Nakano Y, Kawahara-Miki R, Inokuchi M, Yorifuji M, Okubo R, Nagasawa T, Hiroi J, et al (2016) An evolutionary insight into the hatching strategies of pipefish and seahorse embryos. $J$ Exp Zool B Mol Dev Evol 326, 125-35.

6. Kawaguchi M, Yasumasu S, Shimizu A, Hiroi J, Yoshizaki N, Nagata K, Tanokura M, Iuchi I (2005) Purification and gene cloning of Fundulus heteroclitus hatching enzyme. A hatching enzyme system composed of high choriolytic enzyme and low choriolytic enzyme is conserved between two different teleosts,
Fundulus heteroclitus and medaka Oryzias latipes. FEBS J 272, 4315-26.

7. Kawaguchi M, Yasumasu S, Shimizu A, Kudo N, Sano K, Iuchi I, Nishida M (2013) Adaptive evolution of fish hatching enzyme: one amino acid substitution results in differential salt dependency of the enzyme. $J$ Exp Biol 216, 1609-15.

8. Wu XL, Huang QS, Fang C, Ye T, Qiu L, Dong SJ (2012) PFOS induced precocious hatching of Oryzias melastigma - From molecular level to individual level. Chemosphere 87, 703-8.

9. Fan T, Wang J, Yuan W, Zhong Q, Shi Y, Cong R (2010) Purification and characterization of hatching enzyme from brine shrimp Artemia salina. Acta Biochim Biophys Sin (Shanghai) 42, 165-71.

10. Li B, Fan T, Yang L, Cong R, Li L, Sun W, Lu C, Shi Z (2006) Purification and characterization of hatching enzyme from shrimp Penaeus chinensis. Arch Biochem Biophys 451, 188-93.

11. Yasumasu S, Mao KM, Sultana F, Sakaguchi H, Yoshizaki N (2005) Cloning of a quail homologue of hatching enzyme: its conserved function and additional function in egg envelope digestion. Dev Genes Evol 215, 489-98.

12. Hong CS, Saint-Jeannet JP (2014) Xhe2 is a member of the astacin family of metalloproteases that promotes Xenopus hatching. Genesis 52, 946-51.

13. Cohen KL, Piacentino ML, Warkentin KM (2018) The hatching process and mechanisms of adaptive hatching acceleration in hourglass treefrogs, Dendropsophus ebraccatus. Comp Biochem Physiol A Mol Integr Physiol 217, 63-74.

14. Katagiri C, Maeda R, Yamashika C, Mita K, Sargent TD, Yasumasu S (1997) Molecular cloning of Xenopus hatching enzyme and its specific expression in hatching gland cells. Int J Dev Biol 41, 19-25.

15. Lepage T, Gache C (1990) Early expression of a collagenase-like hatching enzyme gene in the sea urchin embryo. EMBO J 9, 3003-12.

16. Bowles VM, Young AR, Barker SC (2008) Metalloproteases and egg-hatching in Pediculus humanus, the body (clothes) louse of humans (Phthiraptera: Insecta). Parasitology 135, 125-30.

17. Foradori MJ, Kovoor J, Moon MJ, Tillinghast EK (2002) Relation between the outer cover of the egg case of Argiope aurantia (Araneae: Araneidae) and the emergence of its spiderlings. $J$ Morphol 252, 218-26.

18. Young AR, Mancuso N, Meeusen EN, Bowles VM (2000) Characterisation of proteases involved in egg hatching of the sheep blowfly, Lucilia cuprina. Int $J$ Parasitol 30, 925-32.

19. Quesada V, Sanchez LM, Alvarez J, Lopez-Otin C (2004) Identification and characterization of human and mouse ovastacin: a novel metalloproteinase similar to hatching enzymes from arthropods, birds, 
amphibians, and fish. $J$ Biol Chem 279, 26627-34.

20. Sawada H, Yamazaki K, Hoshi M (1990) Trypsin-like hatching protease from mouse embryos: Evidence for the presence in culture medium and its enzymatic properties. $J$ Exp Zool 254, 83-7.

21. Hirayama C, Ono H, Meng Y, Shimada T, Daimon $\mathrm{T}$ (2013) Flavonoids from the cocoon of Rondotia menciana. Phytochemistry 94, 108-12.

22. Dong X, Du M (1995) The effect of application of sex pheromone trapping Rondotia menciana. China Sericulture 17-9.

23. Xu M, Zhang Y, Zhu X (1994) Biological properties of mulberry white caterpillar (Rondotia menciana), (Bombycidae) and its control methods. Acta Sericologica Sinica 20, 136-40.

24. Duke SO (2011) Comparing conventional and biotechnology-based pest management. J Agric Food Chem 59, 5793-8.

25. Lu F, Tang S, Shen X, Wang N, Zhao Q, Zhang G, Guo $X$ (2010) Molecular cloning and characterization of hatching enzyme-like gene in the silkworm, Bombyx mori. Mol Biol Rep 37, 1175-82.

26. Tang S, Wu J, Zhao X, Wang H, Qiu Z, Shen X, Guo $X$ (2012) Molecular cloning and characterization of hatching enzyme-like geneII (BmHELII) in the silkworm, Bombyx mori. Biochem Biophys Res Commun 419, 194-9.

27. Tang S, Ding L, Shen X, Wu J, Lu F, Zhou Q, Li $X$ (2011) Full-length cDNA cloning and expression characteristic analysis of hatching enzyme-like gene in the Chinese oak silkworm, Antheraea pernyi. Acta Sericologica Sinica 37, 1000-7.

28. Tang S, Zhao X, Wu J, Qiu Z, Shen X (2011) Cloning and bioinformatics analysis of hatching enzyme gene in Chinese wild silkworm (Bombyx mandarina). Acta Agri Jiangxi 23, 1-5.

29. Chen M, Chen MM, Yao R, Li Y, Wang H, Li Y, Liu Y (2013) Molecular cloning and characterization of two $12 \mathrm{kDa}$ FK506-binding protein genes in the Chinese oak silkworm, Antheraea pernyi. J Agric Food Chem 61, 4599-605.

30. Tang S, Zhao Q, Yi Y, Zhang Z, Li Y (2005) Homologous region 3 from Bombyx mori nucleopolyhedrovirus enhancing the transcriptional activity of heat shock cognate 70-4 promoter from Bombyx mori and Bombyx mandarina in vitro and in vivo. Biosci Biotechnol Biochem 69, 1014-7.

31. Bordoli L, Kiefer F, Arnold K, Benkert P, Battey J, Schwede T (2009) Protein structure homology modeling using SWISS-MODEL workspace. Nature Protocols 4, 1-13.

32. Kawaguchi M, Yasumasu S, Hiroi J, Naruse K, Suzuki T, Iuchi I (2007) Analysis of the exon-intron structures of fish, amphibian, bird and mammalian hatching enzyme genes, with special reference to the intron loss evolution of hatching enzyme genes in
Teleostei. Gene 392, 77-88.

33. Okada A, Sano K, Nagata K, Yasumasu S, Ohtsuka J, Yamamura A, Kubota K, Iuchi I, et al (2010) Crystal structure of zebrafish hatching enzyme 1 from the zebrafish Danio rerio. J Mol Biol 402, 865-78.

34. Geier G, Zwilling R (1998) Cloning and characterization of a cDNA coding for Astacus embryonic astacin, a member of the astacin family of metalloproteases from the crayfish Astacus astacus. Eur J Biochem 253, 796-803.

35. Reyda S, Jacob E, Zwilling R, Stocker W (1999) cDNA cloning, bacterial expression, in vitro renaturation and affinity purification of the zinc endopeptidase astacin. Biochem $J$ 344, 851-7.

36. Young AR, Mancuso N, Bowles VM (1999) Biochemical aspects of egg hatch in endo- and ectoparasites: potential for rational drug design. Int J Parasitol 29, 861-7. 